\title{
Editorial \\ Memorial Issue Dedicated to Dr. Howard D. Flack: The Man behind the Flack Parameter
}

\author{
Catherine E. Housecroft $1, *(\mathbb{D})$ and Katharina M. Fromm ${ }^{2}$ (D) \\ 1 Department of Chemistry, University of Basel, Mattenstrasse 24a, BPR 1096, 4058 Basel, Switzerland \\ 2 Department of Chemistry, University of Fribourg, Chemin du Musée 9, 1700 Fribourg, Switzerland; \\ katharina.fromm@unifr.ch \\ * Correspondence: catherine.housecroft@unibas.ch
}

check for updates

Citation: Housecroft, C.E.; Fromm, K.M. Memorial Issue Dedicated to Dr. Howard D. Flack: The Man behind the Flack Parameter. Chemistry 2021, 3, 818-820. https://doi.org/ 10.3390/chemistry3030058

Received: 23 July 2021

Accepted: 23 July 2021

Published: 27 July 2021

Publisher's Note: MDPI stays neutral with regard to jurisdictional claims in published maps and institutional affiliations.

Copyright: (C) 2021 by the authors Licensee MDPI, Basel, Switzerland. This article is an open access article distributed under the terms and conditions of the Creative Commons Attribution (CC BY) license (https:// creativecommons.org/licenses/by/ $4.0 /)$.
This Special Issue of Chemistry is dedicated to Dr. Howard D. Flack (1943-2017), a renowned crystallographer who transformed the way in which, by using single crystal X-ray diffraction, we are able to determine the absolute structure of a crystalline material, and thereby determine the absolute configuration of molecular species within the material. All of us who routinely use cifs are familiar with the 'Flack Parameter', and the younger generations take it for granted. Not all realize that this is a relatively recent implementation [1].

Howard Flack studied at the University of Cambridge, UK, and moved to a position of Maitre-assistant in the Laboratoire de Cristallographie at the University of Geneva, Switzerland, in 1972. He remained in Geneva working as a crystallographer for his entire career, and contributed his knowledge, enthusiasm and encouragement to the establishment of crystallographic facilities at other Swiss universities. His invaluable computational and scholarly contributions to single-crystal X-ray diffraction have left an extraordinary mark on the field, as can be appreciated by the bibliography of the Howard Flack's publications contributed to this Special Issue by Constable [2].

As noted above, Howard Flack is probably most associated with the Flack parameter, which is routinely reported for all chiral molecules for which-single crystal X-ray diffraction data are reported in the literature. Watkin and Cooper provide an excellent account of the importance and applications of the Flack parameter, and conclude their paper with some advice on its use [3]. Complementing this, Constable and Housecroft have focused on the development of crystallographic methods within metal coordination chemistry, and demonstrated the role of the Flack parameter in providing a routine method for determining the absolute configuration of coordination compounds [4]. The contributions made by Howard Flack in providing tools for crystallographers to take account of crystal twinning in structure elucidation are represented in the paper by Øien-Ødegaard and Lillerud, which describes the crystal structures of three zirconium-containing metal-organic frameworks determined from twinned crystals [5].

At the heart of a crystal lattice are intermolecular interactions. Tools to analyze structures in terms of these weak interactions are widely available, starting from the molecular structure, although predicting the crystalline assembly is far from straight forward. Aakeröy and coworkers approached this challenge using energy- and informaticsbased prediction models founded on molecular electrostatic potentials, hydrogen-bond energies, propensity and coordination. They have applied these criteria to the crystal structures of twelve pyrazole-based molecules in order to explore the ability to correctly predict supramolecular synthons [6]. Remaining with the theme of crystal engineering, Černý et al. present a review of the crystal chemistry of inorganic hydroborates. This detailed review deals with salts containing hydroborate ions as the only type of anion. The structural patterns that emerge from this investigation should be invaluable to those interested in the design of hydroborate-based materials [7]. 
An octahedral metal center coordinated by three bidentate ligands, e.g., $\left[\mathrm{M}\left(2,2^{\prime}\right.\right.$ bipyridine $\left.)_{3}\right]^{n+}$, is the archetypal coordination motif that chemistry undergraduates learn can possess a $\Delta$ - or $\Lambda$-configuration. Lappin and coworkers have redetermined the singlecrystal structure of $\Lambda-\left[\mathrm{Co}(\text { en })_{3}\right] \Delta-[\mathrm{Co}(\text { edta })]_{2} \mathrm{Cl} \cdot 10 \mathrm{H}_{2} \mathrm{O}$ at low temperature, and they also report the structure of racemic $[\mathrm{Co}(\mathrm{sep})][\mathrm{Co}(\mathrm{edta})] \mathrm{Cl}_{2} \cdot 2 \mathrm{H}_{2} \mathrm{O}$. The former provides valuable insight into chelate ring conformation and hydrogen bonded interactions in the lattice. The data serve to provide a better understanding of stereoselectivity in ion-pairing and electron transfer reactions [8]. Piguet and coworkers present a detailed investigation of pseudooctahedral spin-crossover $\left[\mathrm{Fe}(\mathrm{L})_{3}\right]^{2+}$ complexes, in which $\mathrm{L}$ is an unsymmetrical and sterically demanding $\alpha, \alpha^{\prime}$-diimine ligand [9]. The theme of metal coordination chemistry continues with a contribution from McKenzie and coworkers, describing the chemisorption of gaseous NO by the enantiomorphic phases of the cobalt coordination compounds containing a chiral salen ligand [10]. Six-, seven- and eight-coordinate lanthanoid (Ln) metal complexes of types cis-[ $\left.\left.\mathrm{Ln}(\mathrm{dppmO})_{2}\right)_{2} \mathrm{Cl}_{2}\right] \mathrm{Cl}$, $\left[\mathrm{Ln}(\mathrm{dppmO})_{3}\right)_{3} \mathrm{Cl}_{\mathrm{Cl}} \mathrm{Cl}_{2}$ and $\left[\mathrm{Ln}(\mathrm{dppmO})_{4}\right)_{4} \mathrm{Cl}_{3}$ are reported by Reid and coworkers; the dependence of the coordination number and geometry on the $\mathrm{Ln}^{3+}$ radius, and the role of the chloride ions are discussed [11].

Small molecules and their crystal structures are the focus of several contributions to this Special Issue. Bauer and Götz present the crystal structure of chloropentaphenyldisiloxane and highlight intermolecular interactions in monofunctionalized disiloxanes [12]. A new synthetic approach to arylsulfonates has been exemplified by Ngassa and coworkers by the preparation of a series of substituted nitrophenyl- $4^{\prime}$-phenylbenzenesulfonates; structural characterizations provide insight into the intermolecular interactions in these species [13]. This structural discussion is complemented by the contribution from Seidel et al., which reports the structural characterization of $(R)$-and rac-2-bromo-3-methylbutanoic acid with particular focus on hydrogen-bonded motifs and conformational preferences observed in the solid-state [14]. In a related study, Lehmann and coworkers describe the determination of the absolute configuration of the flavoring agent $(+)-\gamma$-decalactone; crystal growth was achieved in situ by cryo-crystallization methods [15]. Rifamycins are an important group of antibacterial agents, and in their contribution to this Special Issue, Frampton et al. report the structural characterization and absolute stereochemistry of a semi-synthetic rifamycin which was prepared using an Alder-Ene addition [16].

A fascinating illustration of the application of Erdmann's anion, trans- $\left[\mathrm{Co}\left(\mathrm{NH}_{3}\right)_{2}\left(\mathrm{NO}_{2}\right)_{4}\right]^{-}$, in the isolation and crystallization of impounded street drugs is provided by Lalancette and coworkers; using salts of cocaine, methamphetamine and methylone, single-crystal structural data were used to calculate powder X-ray diffraction patterns, giving a means for rapid screening of confiscated materials [17].

We are indebted to all the contributors to this Special Issue which provides a timely opportunity to pay tribute to Howard Flack — the man behind the Flack parameter and more.

Conflicts of Interest: The authors declare no conflict of interest.

\section{References}

1. Flack, H.D. On enantiomorph-polarity estimation. Acta Cryst. 1983, A39, 876-881. [CrossRef]

2. Constable, E.C. The Publications of Howard Flack (1943-2017). Chemistry 2020, 2, 40. [CrossRef]

3. Watkin, D.J.; Cooper, R.I. Howard Flack and the Flack Parameter. Chemistry 2020, 2, 52. [CrossRef]

4. Constable, E.C.; Housecroft, C.E. When Stereochemistry Raised Its Ugly Head in Coordination Chemistry-An Appreciation of Howard Flack. Chemistry 2020, 2, 49. [CrossRef]

5. Øien-Ødegaard, S.; Lillerud, K.P. Twinning in Zr-Based Metal-Organic Framework Crystals. Chemistry 2020, 2, 50. [CrossRef]

6. Sandhu, B.; McLean, A.; Sinha, A.S.; Desper, J.; Aakeröy, C.B. Assessment of Computational Tools for Predicting Supramolecular Synthons. Chemistry 2021, 3, 43. [CrossRef]

7. Černý, R.; Brighi, M.; Murgia, F. The Crystal Chemistry of Inorganic Hydroborates. Chemistry 2020, 2, 53. [CrossRef]

8. Osvath, P.; Oliver, A.; Lappin, A.G. Stereosopecificity in [Co(sep)][Co(edta) $] \mathrm{Cl}_{2} \cdot 2 \mathrm{H}_{2} \mathrm{O}$. Chemistry 2021, 3, 17. [CrossRef]

9. Deorukhkar, N.; Lathion, T.; Guénée, L.; Besnard, C.; Piguet, C. The Tyranny of Arm-Wrestling Methyls on Iron(II) Spin State in Pseudo-Octahedral [Fe(didentate) 3 ] Complexes. Chemistry 2020, 2, 15. [CrossRef]

10. Møller, M.D.; Liljedahl, M.C.; McKee, V.; McKenzie, C.J. Solid Phase Nitrosylation of Enantiomeric Cobalt(II) Complexes. Chemistry 2021, 3, 41. [CrossRef] 
11. Bannister, R.D.; Levason, W.; Reid, G. Bis(diphenylphosphino)methane Dioxide Complexes of Lanthanide Trichlorides: Synthesis, Structures and Spectroscopy. Chemistry 2020, 2, 60. [CrossRef]

12. Bauer, J.; Götz, T. Chloropentaphenyldisiloxane-Model Study on Intermolecular Interactions in the Crystal Structure of a Monofunctionalized Disiloxane. Chemistry 2021, 3, 33. [CrossRef]

13. Stenfors, B.A.; Staples, R.J.; Biros, S.M.; Ngassa, F.N. Synthesis and Crystallographic Characterization of X-Substituted 2,4Dinitrophenyl-4'-phenylbenzenesulfonates. Chemistry 2020, 2, 36. [CrossRef]

14. Seidel, R.W.; Nöthling, N.; Goddard, R.; Lehmann, C.W. Structural Elucidation of Enantiopure and Racemic 2-Bromo-3Methylbutyric Acid. Chemistry 2020, 2, 44. [CrossRef]

15. Patzer, M.; Nöthling, N.; Goddard, R.; Lehmann, C.W. Absolute Configuration of In Situ Crystallized (+)- $\gamma$-Decalactone. Chemistry 2021, 3, 40. [CrossRef]

16. Frampton, C.S.; Gall, J.H.; MacNicol, D.D. Novel Ansa-Chain Conformation of a Semi-Synthetic Rifamycin Prepared Employing the Alder-Ene Reaction: Crystal Structure and Absolute Stereochemistry. Chemistry 2021, 3, 52. [CrossRef]

17. Wood, M.R.; Mikhael, S.; Bernal, I.; Lalancette, R.A. Erdmann's Anion—An Inexpensive and Useful Species for the Crystallization of Illicit Drugs after Street Confiscations. Chemistry 2021, 3, 42. [CrossRef] 